\title{
Radiative properties and direct effect of Saharan dust measured by the C-130 aircraft during Saharan Dust Experiment (SHADE): 2. Terrestrial spectrum
}

\author{
Eleanor J. Highwood, ${ }^{1}$ James M. Haywood, ${ }^{2}$ Michael D. Silverstone, ${ }^{1,3}$ \\ Stuart M. Newman, ${ }^{2}$ and Jonathan P. Taylor ${ }^{2}$ \\ Received 21 May 2002; revised 11 September 2002; accepted 15 January 2003; published 24 July 2003.
}

[1] In situ measurements of terrestrial radiation from the C-130 aircraft during the Saharan Dust Experiment (SHADE) are used to quantify the effect of a strong dust outbreak on radiance and brightness temperatures. The dust gives a distinct spectral signature in upwelling and downwelling terrestrial radiation when high spectral resolution data for a dusty day is compared to data from a clear day. A radiative transfer model is used together with a size distribution retrieved from Sun photometers and atmospheric profiles from dropsondes to simulate the radiance data and provide a constraint on the refractive indices of Saharan dust in the terrestrial part of the spectrum. The degree of agreement between observed and simulated brightness temperatures is dominated by the choice of refractive index, the mass loading, and the altitude of the dust layer. The uncertainties in size distribution appear to have less of an effect so long as large particles (radius greater than $1 \mu \mathrm{m}$ ) are included. In the terrestrial spectrum the dust produced a relative warming rate of up to $0.5 \mathrm{~K}$ /day below the dust and a relative cooling of up to $0.5 \mathrm{~K} /$ day within the dust layer itself. The effect on irradiance due to this dust outbreak was a decrease in upwelling terrestrial radiation at the top of the atmosphere of $6.5 \mathrm{Wm}^{-2}$ and an increase in downwelling terrestrial radiation at the surface of $11.5 \mathrm{Wm}^{-2}$. The dust led to decreases in brightness temperature of $2-4 \mathrm{~K}$ in the window region, consistent with apparent features in the sea surface temperature retrieved from the advanced very high resolution radiometer. INDEX TERMS: 0305 Atmospheric Composition and Structure: Aerosols and particles (0345, 4801); 3359 Meteorology and Atmospheric Dynamics: Radiative processes; 3394 Meteorology and Atmospheric Dynamics: Instruments and techniques; KEYWORDS: dust, refractive index, direct effect, terrestrial radiation, aircraft measurements

Citation: Highwood, E. J., J. M. Haywood, M. D. Silverstone, S. M. Newman, and J. P. Taylor, Radiative properties and direct effect of Saharan dust measured by the C-130 aircraft during Saharan Dust Experiment (SHADE): 2. Terrestrial spectrum, J. Geophys. Res., 108(D18), 8578, doi:10.1029/2002JD002552, 2003.

\section{Introduction}

[2] While substantial attention has been paid to the significant effect of mineral dust on solar radiation in recent years [e.g., Sokolik et al., 2001, and references therein], relatively little study has been completed on quantification of the impact of dust on terrestrial radiation. Radiative transfer models have shown that there is the potential for dust to act in a manner analogous to greenhouse gases, depending particularly on the height of the dust and the nature of the underlying surface and the presence of cloud [e.g., Sokolik and Toon, 1996; Quijano et al., 2000]. Sokolik et al. [1998] calculated the impact on terrestrial irradiance in

\footnotetext{
${ }^{1}$ Department of Meteorology, University of Reading, UK.

${ }^{2}$ Met Office, Bracknell, UK.

${ }^{3}$ Now at Met Office, Bracknell, UK.
}

a heavy dust loading scenario as being between +15 and $+25 \mathrm{Wm}^{-2}$ at the top of the atmosphere and -50 to $-80 \mathrm{Wm}^{-2}$ at the surface. Myhre and Stordal [2001] found a terrestrial radiative forcing of between 0.04 and 1.13 $\mathrm{Wm}^{-2}$ due to the total dust in the atmosphere and between 0.02 and $0.24 \mathrm{Wm}^{-2}$ for the anthropogenic component of this forcing. The results depended on the geographical distribution and optical properties used.

[3] Many of the studies of dust terrestrial radiative forcing use idealized aerosol properties at these wavelengths. One reason for this has been the almost total lack of observations of optical properties of dust in the terrestrial to date. The refractive indices used in many climate models are those of the "dust-like" aerosol of the World Climate Program $(W C P)$ [1986] and are based on Volz [1972]. There have been a few measurements of the refractive index of bulk dust samples measured in the laboratory from samples collected during dust outbreaks (e.g., Volz [1973] concerning Saharan dust collected at Barbados, and Fouquart et al. [1987] who use measurements of Saharan dust over Niger). More re- 
cently the importance of the different chemical compositions of dust from different source areas has been highlighted by Sokolik and Toon [1999] and refractive indices for individual mineralogical components have become more widely available. Only some of this data is relevant to airborne dust, which is what is necessary for calculating the radiative effect.

[4] Regionally the direct impact of dust on solar radiation has been measured as up to $-60 \mathrm{Wm}^{-2}$ over ocean during a Saharan dust outbreak [Haywood et al., 2001]. Few in situ measurements are available of the impact on the terrestrial radiation. Haywood et al. [2001] found that measurements in a dusty atmosphere could not be said to be significantly different from the clear sky situation once the errors of the broadband pyrgeometer instrumentation and errors associated with modeling were taken into consideration. However, Haywood et al. [2001] state that these measurements do not imply that the effect of mineral dust in the terrestrial region of the spectrum is negligible, rather that the errors in the atmospheric profile of temperature, water vapor, and mineral dust and the underlying surface temperature confound detection in such simple instrumentation.

[5] Satellite instruments allow quasi-continuous observations of Saharan dust outbreaks. In addition, the presence of Saharan dust can affect the retrieval of other variables such as sea surface temperature. Indeed, the motivation for this study comes partly from observing an interesting feature in satellite derived sea surface temperatures during a particularly heavy outbreak measured during the Saharan Dust Experiment (SHADE) campaign.

[6] A particularly thick dust cloud was observed during flight A797 on 25 September 2001 where the aerosol optical depth at a wavelength of $0.55 \mu \mathrm{m}, \tau_{a e r \lambda=0.55}$, was calculated to exceed 1.5 [see Haywood et al., 2003]. This high optical depth offers the best chance of detecting and quantifying any impact in the terrestrial region of the spectrum. This paper discusses measurements and modeling of the terrestrial radiative effect of the Saharan dust cloud on this day. In particular, high spectral resolution measurements from the Airborne Research Interferometer Evaluation Instrument (ARIES) are presented, showing a spectral signature of dust in terrestrial radiation. A sophisticated radiative transfer model is used to simulate the observations, attempting "closure" between in situ measurements of radiation and model calculations using measured aerosol properties. This work also allows the deduction of an appropriate refractive index describing this airborne Saharan dust in the terrestrial part of the spectrum. This work may be considered complementary to the study of Haywood et al. [2003] who examine the solar radiative effect of Saharan dust during the SHADE campaign.

[7] Section 2 describes the relevant instrumentation used while section 3 describes the measurements of terrestrial radiative effect. Section 4 discusses the radiative transfer model and methods used for describing the optical properties of the aerosol and presents the results of the model and observation comparison. Section 5 shows the effect that the Saharan dust has on the retrieval of advanced very high resolution radiometer (AVHRR) sea surface temperatures (SSTs). Section 6 presents a discussion and conclusions.

\section{C-130 Flight Patterns and Relevant Instrumentation}

[8] The flight pattern flown by the C-130 on 25 September 2000 (A797) is shown schematically by Haywood et al. [2003], and is not repeated in detail here. Briefly, the aircraft flew a series of straight and level runs (SLRs) above, below and within the aerosol layer with profile ascents and descents in between. The analysis presented here concentrates in detail on the measurements made above the aerosol layer (R6), and below the aerosol layer (R10). R6 was performed from Dakar where the dust layer was optically quite thick $\left(\tau_{a e r \lambda=0.55}>1.6\right)$ toward an optically thinner layer over Sal $\left(\tau_{a e r \lambda=0.55}=0.58\right)$ and was of approximately 55 min duration. R10 was performed beneath the aerosol layer at an altitude of approximately $30 \mathrm{~m}$ above sea level and consisted of an into- and downSun leg each of approximately 10 min duration. In addition, data from SLRs during a flight when negligible concentrations of Saharan dust were present (A795) is also investigated for comparison purposes.

[9] The aerosol and solar radiation instrumentation used on board the C-130 in this measurement campaign is more fully described by Haywood et al. [2003]. Here we restrict ourselves to discussion of the instrumentation used for measurements of terrestrial radiation. Upward and downward facing pyrgeometers developed by Foot [1986] cover the entire region of the terrestrial spectrum $(3-50 \mu \mathrm{m})$. However, the estimated errors in the measurements exclude these broadband radiometers from definitive determination of the measured radiative impact, since the accuracy of the broadband measurement is estimated to be approximately $\pm 10 \mathrm{Wm}^{-2}$, of similar size to the likely magnitude of radiative effect discussed in the previous section.

[10] In the context of satellite retrievals it is of utmost importance to know the spectral distribution of radiative effect, either to detect dust in terrestrial radiation or to remove the effect. The Airborne Research Interferometer Evaluation System (ARIES), was used to measure radiances at a spectral resolution of approximately $0.5 \mathrm{~cm}^{-1}$. These radiances are then converted to brightness temperatures. Data used in this paper includes nadir view data collected during straight and level runs of the aircraft when flying above the aerosol layer (R6), and zenith views collected when the aircraft was flying at low level below the aerosol layer (R10). Similar measurements were also made on a day when there was no dust layer present. Comparing the two sets of measurements can therefore be used to quantify the reduction in upwelling terrestrial radiation caused by the absorption and re-emission of radiation by the dust layer (nadir views) and the downwelling terrestrial radiation emitted by the dust layer (zenith views). Newman and Taylor [2002] have shown that ARIES brightness temperatures in the window region may be modeled to within a few tenths of a degree when aerosol and cloud are absent from the atmosphere.

\section{Radiative Effect Measurements}

[11] The measurements of dust optical properties and the large radiative effect on short wave radiation during flight A797 of the SHADE campaign have been examined by 
Haywood et al. [2003]. Here attention is focused on the ARIES measurements taken in the range $600-1400 \mathrm{~cm}^{-1}$ which includes the atmospheric window region. In the window region of the spectrum the absence of strong absorption by water vapor and carbon dioxide should allow a clear spectral signal of the impact of dust to emerge. The only other gaseous absorptions in this region are the strong ozone band at $9.6 \mu \mathrm{m}$ and a weak contribution from the water vapor continuum.

\subsection{Nadir View}

[12] Figure 1 shows high-resolution ARIES data in the atmospheric window, taken during R6 of flight A797 on 25 September and during R1 of flight A795 on the 21 September. For the A797 flight the measurements shown are averaged over a $5 \mathrm{~min}$ period in the center of the run, where the broadband radiometers showed a relatively constant reflection of solar radiation by the dust. For the clear sky A795 case the data is an average over the entire run. ARIES was looking down at the dust layer (or the clear sky in A795) from an altitude of approximately $5000 \mathrm{~m}$ measuring the upward terrestrial radiance. The radiances were subsequently converted to brightness temperature.

[13] Figure 1a shows the comparison of brightness temperatures between a clear sky measurement from A795 (dotted line) and the dusty sky measurement from A797 (solid line). In both cases the ozone absorption band in the center of the window is clearly visible. The spectral variation of radiance is markedly different between the two measurements; the clear sky case showing much less variation with wave number between 800 and $1200 \mathrm{~cm}^{-1}$. However, it is difficult to make a quantitative comparison since the sea surface temperatures were not identical during the two runs as the measurements during A795 were performed some $6^{\circ}$ of latitude further north than the measurements taken during A797.

[14] We can remove this problem to some extent by assuming that the atmosphere was broadly similar on the two days. Measurements of sea surface temperature taken from the C-130 during low-level runs on both days were used to calculate the mean sea surface temperature and showed a 5.6 K warmer surface during flight A797. This temperature difference was then added uniformly at all wavelengths to the clear sky run brightness temperature. (While this is justifiable in the transparent window region between 750 and $1200 \mathrm{~cm}^{-1}$ it is not a good method in the strong $\mathrm{CO}_{2}$ band centered at $670 \mathrm{~cm}^{-1}$ and at wave numbers greater than approximately $1250 \mathrm{~cm}^{-1}$ due to increasingly strong water vapor and methane absorption lines. In these regions the retrieved brightness temperature is sensitive to the temperature of the atmospheric profile just below the aircraft. Additionally the sharp differences coinciding with water vapor lines are affected by day-to-day changes in the atmospheric profile of humidity.) The new comparison is shown in Figure $1 \mathrm{~b}$ and the difference in radiance between the two cases (dusty to clear) is shown in Figure 1c.

[15] From Figure 1c it is evident that the dust has an impact on brightness temperature across the window region such that the temperature observed is $2-4 \mathrm{~K}$ cooler when dust is present. This is due to the absorption of terrestrial radiation from the surface by the dust and the re-emission at a lower temperature by the dust layer. There is also
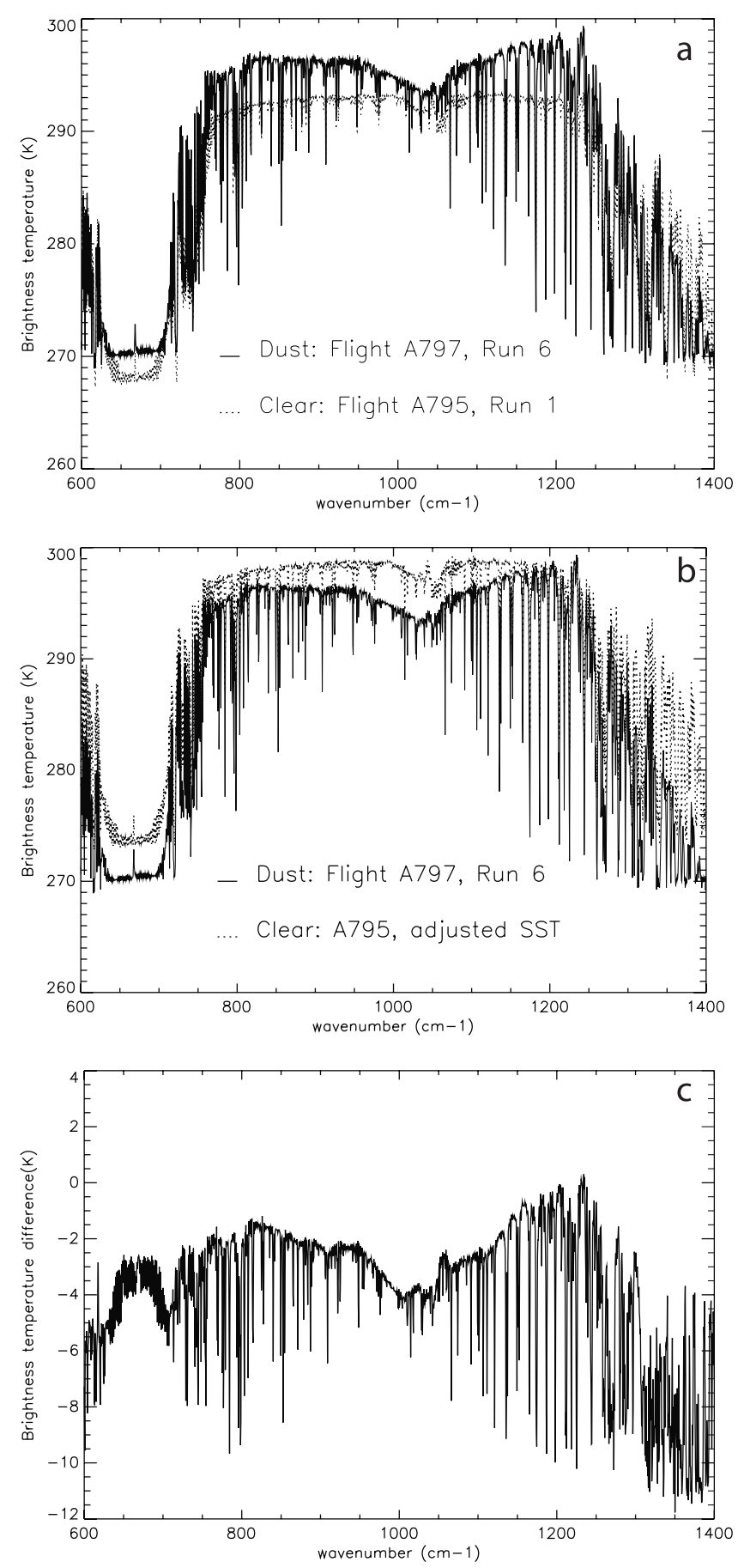

Figure 1. Brightness temperature as a function of wave number in the atmospheric window region calculated from nadir view ARIES measurements taken during run 6 of SHADE flight A797 (dust) and run 1 of A795 (clear). (a) Solid line A797, dashed line A795. (b) Same as Figure la but, clear sky brightness temperature has been increased by the difference in sea surface temperature between the two runs. (c) Spectral signal, dust; clear measurements.

considerable spectral variation of the difference, i.e., the radiative effect has a distinct spectral signature that could perhaps be used to detect the impact of dust in satellite retrievals if multichannel information is available. Interest- 

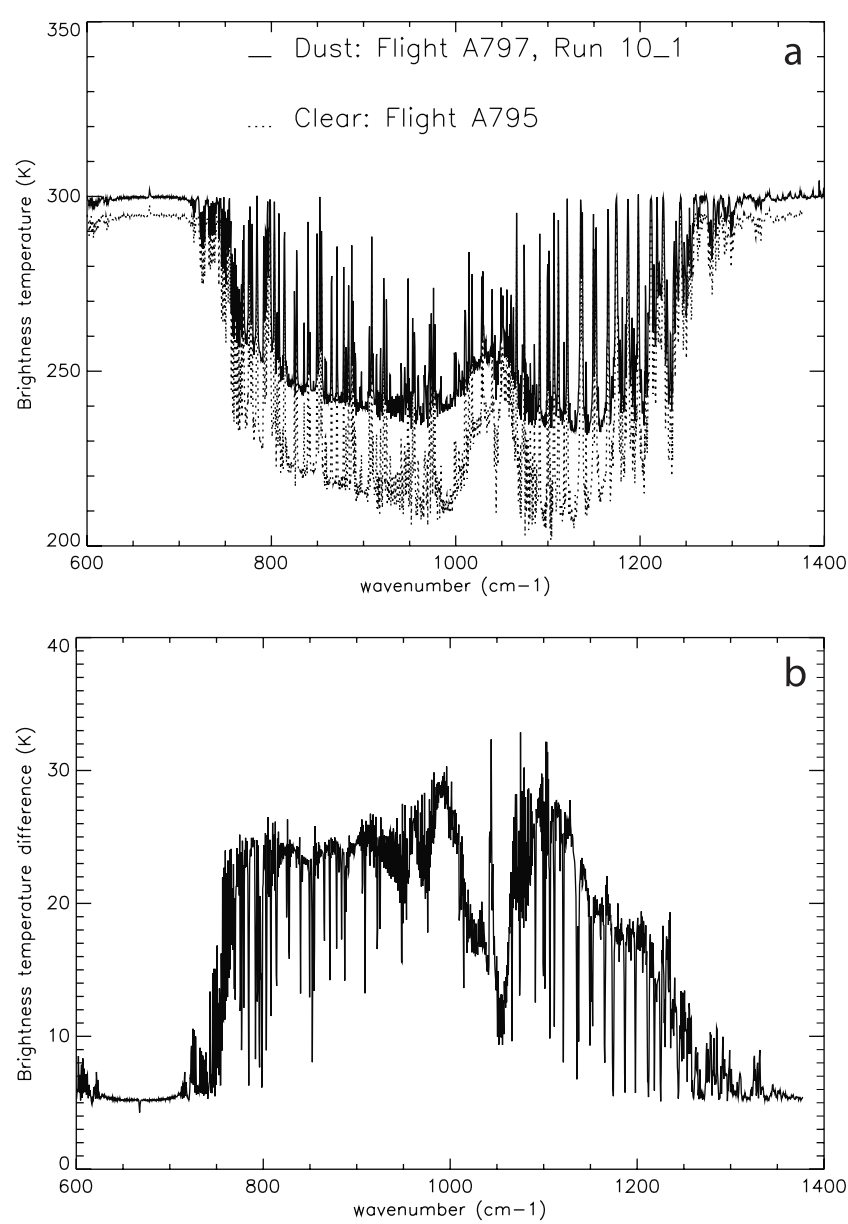

Figure 2. Brightness temperature as a function of wave number in the atmospheric window region calculated from zenith view ARIES measurements taken during run 10 1 of SHADE flight A797 (dust) and run X of A795 (clear). (a) Solid line A797, dashed line A795. (b) Spectral signal, dust; clear measurements.

ingly, the spectral signal is particularly strong close to the absorption band of ozone.

\subsection{Zenith View}

[16] Figure 2a shows ARIES measurements using the zenith view while the aircraft was flying at low level below the dust (run 10). On the day with dust in the atmosphere the brightness temperature measured by ARIES is considerably greater than that measured on the clear day. ARIES is effectively measuring the terrestrial radiation emitted back toward the Earths surface by the dust layer; in the absence of the dust it measures emission from a layer higher in the atmosphere which is therefore colder.

[17] The spectral signature of dust in the brightness temperatures measured below the layer is shown in Figure $2 \mathrm{~b}$. As in the case of the nadir views discussed in the previous section there is considerable spectral variation in the difference. In this view the magnitude of the signal is reduced in the ozone band in the center of the atmospheric window, presumably because there is more terrestrial radiation emitted toward the surface in a clear sky case in this region of the spectrum. The magnitude of the difference is approximately $20 \mathrm{~K}$, much greater than that seen above the dust layer. This indicates that the terrestrial radiation below the dust is more sensitive to the presence of dust and perhaps indicates that a ground-based version of ARIES would be extremely useful in testing for the presence of dust in the atmosphere. However, these views are also more dependent on the knowledge of the other properties of the atmospheric column above the dust and the usefulness is likely to be limited by errors in our knowledge of the humidity profile.

\section{Modeling the Radiative Effect of Dust}

[18] Having observed a spectral signature in the atmospheric window region, this must now be attributed conclusively to the presence of dust. Given that there are many relatively large uncertainties in the aerosol properties such as size distribution, refractive index and mass loading, it is also necessary to systematically examine the sensitivity of our results to these uncertainties. In order to do this a radiance model is used, a version of the radiative transfer model of Edwards and Slingo [1996]. The radiance version of this model is computationally expensive. Since the parameter space is large, our modeling has been restricted to the atmospheric window region where the signal from dust is expected to be largest and most clear. Once the most appropriate set of aerosol parameters has been established through comparison of modeled brightness temperatures with in situ measurements, an irradiance version of the same radiative transfer model is used to calculate the radiative effect of the dust.

\subsection{Radiative Transfer Model and Atmospheric Profiles}

[19] The model used was a radiance version of Edwards and Slingo [1996]. Absorption due to carbon dioxide, ozone, water vapor (including continuum), methane, nitrous oxide, CFC-11 and CFC-12 was included. The surface emissivity in the radiance runs was calculated using the Masuda et al. [1998] model for sea surface emissivity, with values in the approximate range 0.97 to 0.99 in the atmospheric window. The model was used at $10 \mathrm{~cm}^{-1}$ spectral resolution and results are presented here for the spectral region between 600 and $1400 \mathrm{~cm}^{-1}$. Atmospheric profiles of temperature and water vapor were obtained from the dropsondes released during run 6 of flight A797. The ozone profile was taken from measurements on the aircraft made during a profile ascent over the ocean. These profiles are shown in Figures $3 a-3 c$. Above the flight level, two radiosonde ascents made on the same day at Dakar were used to give a temperature and water vapor profile to the top of the atmosphere. The ozone profile was extended to levels above the highest flight level of the aircraft using a climatological tropical ozone profile from McClatchley et al. [1972]. An average of each of these profiles was degraded in vertical resolution to allow a feasible number of levels to be used in the calculation (48 atmospheric levels).

[20] The dust profile was taken from an average of the profiles of number concentration measured on the aircraft during profiles 9 and 14 and is shown in Figure 3d. Again the vertical resolution was necessarily degraded for use in 

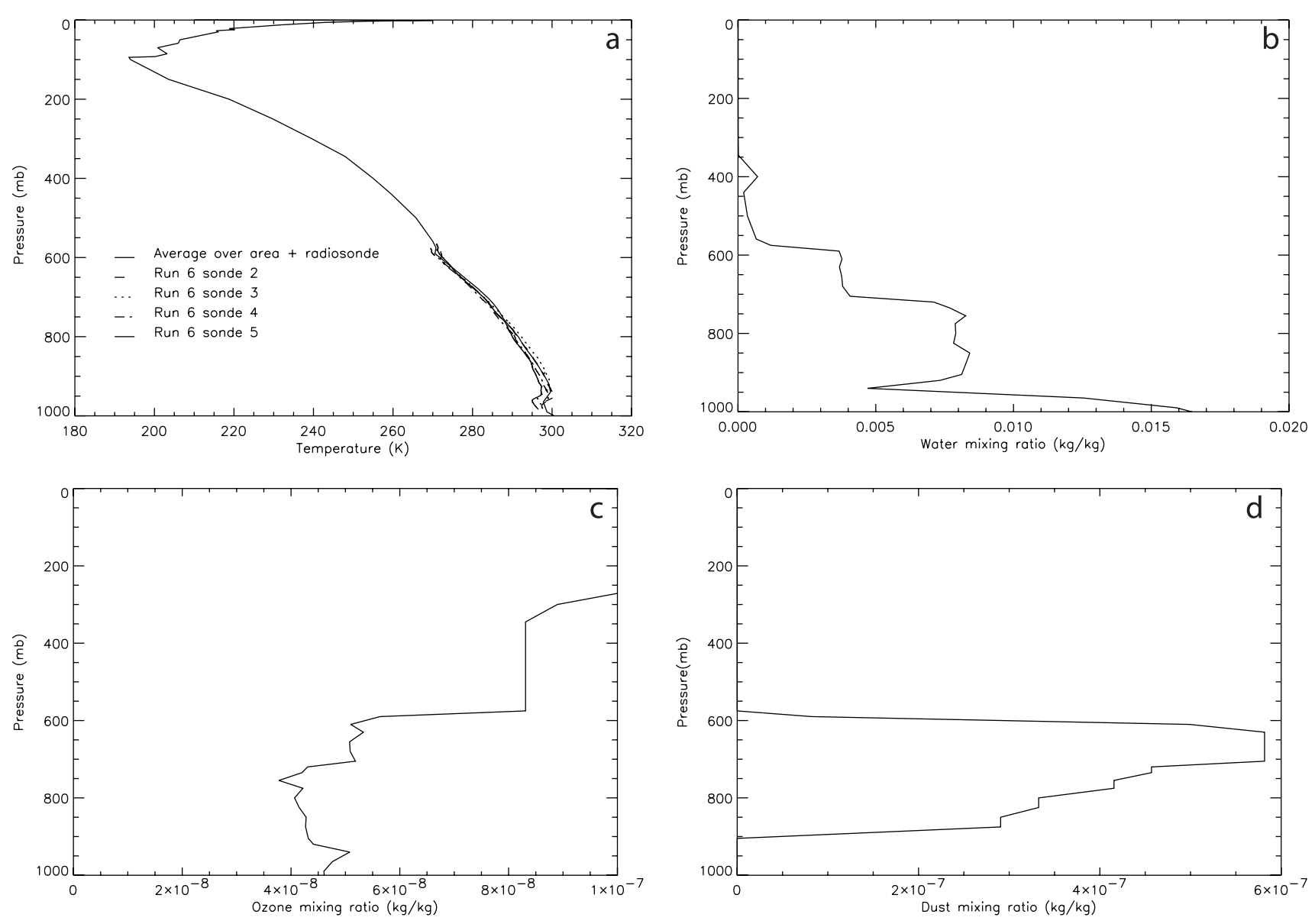

Figure 3. Profiles used in radiative transfer modeling. (a) Temperature averaged from dropsondes and aircraft profile measurements over the region (solid line); also shown below $600 \mathrm{mb}$ are the temperatures measured from dropsondes released during run 6 of flight A797. (b) Water vapor mass mixing ratio in $\mathrm{kg}$ $\mathrm{kg}^{-1}$. (c) Ozone mass mixing ratio in $\mathrm{kg} \mathrm{kg}^{-1}$. (d) Dust mass mixing ratio in $\mathrm{kg} \mathrm{kg}^{-1}$ corresponding to an optical depth at $0.55 \mu \mathrm{m}$ of 0.67 .

the model. Throughout the majority of the modeling work the shape of the dust profile remained constant, however the mass mixing ratios were scaled to give differing total column optical depths as necessary.

\subsection{Aerosol Optical Properties in the Terrestrial Spectrum}

[21] As discussed in section 1, there are very few measurements of optical properties in the terrestrial spectrum. We have used Mie scattering, measured size distributions that are consistent with the optical measurements at solar wavelengths that were made during this flight and are described in detail by Haywood et al. [2003] and various estimates of the refractive index of dust at these wavelengths to calculate the extinction and scattering properties in the terrestrial spectrum. Thus although we have no measurements with which to constrain the optical properties of dust within the terrestrial spectrum, the modeled optical properties are constrained in terms of size distribution by the solar measurements. This consistent methodology allows the investigation of the effect of the known large uncertainties in refractive index at terrestrial wavelengths to be investigated and takes advantage of the relative wealth of measurements and constraints on the refractive index at solar wavelengths. The use of Mie scattering necessarily assumes the dust to be spherical. There are many observations that dust particles at least are certainly not spherical. Mishchenko et al. [1997] showed that the effect of nonsphericity upon calculated single scattering properties can lead to uncertainties of 10 to $15 \%$ in solar regions of the spectrum. The effects of nonsphericity are not considered in this study, due partly to the difficulty of correcting properties without knowing the morphology of the dust.

[22] The aerosol size distributions used are taken from retrievals of column averaged volume distributions from the ground-based Sun photometer at Sal. Nakajima et al. [1996], Dubovik and King [2000], and Dubovik et al. [2002] type retrievals are considered initially. The Nakajima retrievals assume a refractive index to retrieve aerosol optical properties while the other two methods are less constrained retrievals. Although Sun photometer data was also available from Dakar at the other end of the dust cloud through which flights were made, this site was affected by sporadic cloud cover making the column retrievals of aerosol amount problematic. The size distributions measured on the aircraft cannot be used for radiative calculations in the terrestrial because of the failure of the Fast Forward Scattering Spectrometer (FSSP) probe to include 

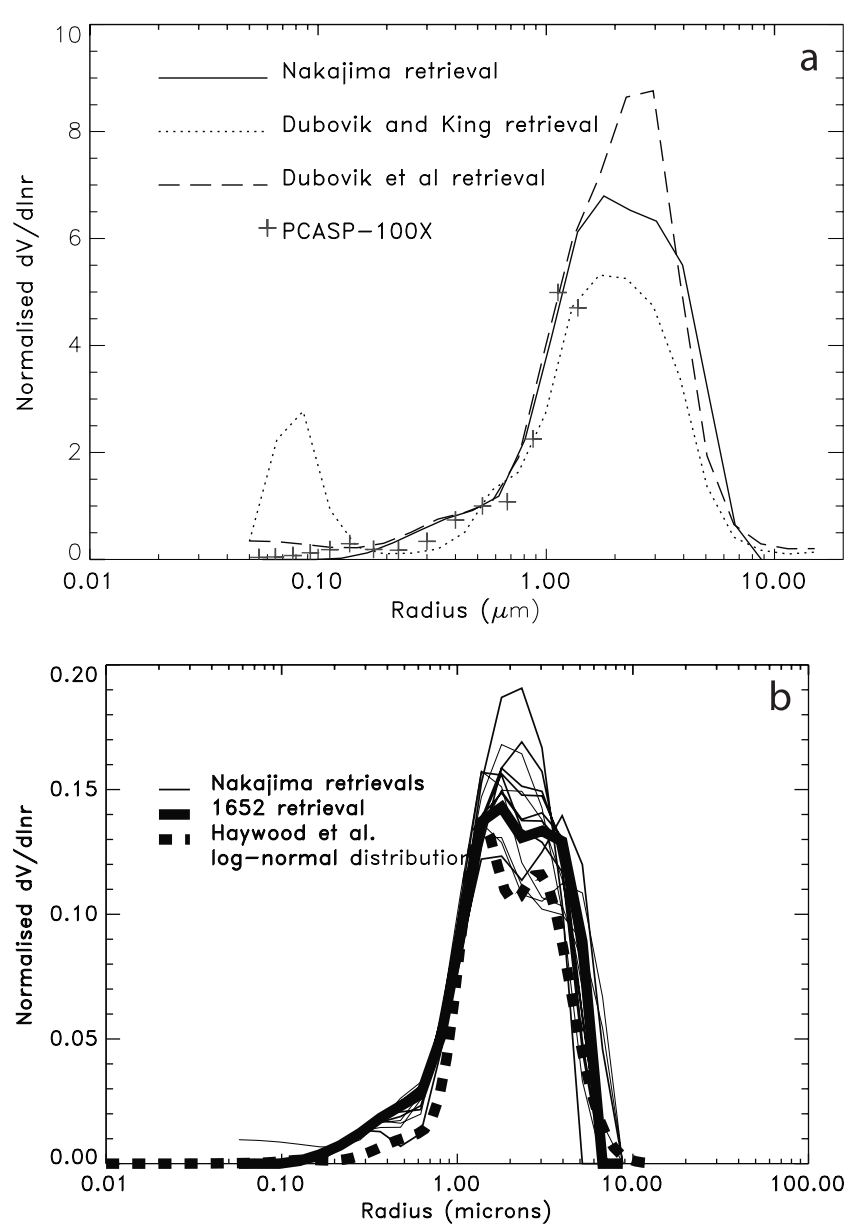

Figure 4. Volume distributions of Saharan dust. (a) Aircraft instrument PCASP measured distribution compared with three retrievals from ground-based Sun photometer at Sal showing no large particles measured by PCASP. Solid line is average of all Nakajima et al. [1996] retrievals from Sal during 25 September; dotted line is average of all Dubovik and King [2000] type retrievals, and dashed line is a Dubovik et al. [2002] type retrieval. (b) Nakajima et al. [1996] type retrievals at Sal during flight A797. Heavy solid curve shows the 1652 retrieval subsequently used in modeling in this study for reasons described in section 4.2; heavy dashed curve shows volume distribution from a 5 mode lognormal distribution fitted to the in situ PCASP measurements (smallest 4 modes) and the Sun photometer data (largest mode) as is used by Haywood et al. [2003].

large dust particles possibly due to their asphericity (see Haywood et al. [2003] for more details). This problem is shown in Figure 4a. The average volume distributions from the Sun photometer using 3 different retrieval algorithms show a significant number of particles present with radii greater than $1 \mu \mathrm{m}$, precisely the particles that are important for interacting with terrestrial radiation. The crosses depict the measurements from the $\mathrm{C}-130$ and show particles up to $1.5 \mu \mathrm{m}$ radius which is the Passive Cavity Aerosol Spectrometer Probe (PCASP) maximum detection radius. The Dubovik and King [2000] retrievals show an artifact at low radii, while the Dubovik et al. [2002] retrievals show some improvement.
[23] To test the sensitivity of aerosol optical properties at terrestrial spectrum wavelengths, Mie scattering calculations were completed using 3 size distributions, a Nakajima et al. [1996] distribution, a Dubovik and King [2000] distribution and a Dubovik et al. [2002] retrieval. The single scattering properties were virtually identical at these wavelengths, certainly being much less sensitive to size distribution than to other quantities such as refractive index. Modeling work here therefore uses one of the Nakajima retrievals of aerosol distribution taken from the Sal Sun photometer at 16:52 on 25 September. This was chosen since it was the closest reliable retrieval to the time of the ARIES measurements in run 6 and given that the other readily available retrieval, that of Dubovik and King [2000] has an artifact at radii less than approximately $0.1 \mu \mathrm{m}$. Figure $4 \mathrm{~b}$ demonstrates that this individual retrieved size distribution falls centrally within those retrieved throughout the day at Sal. It is also in good agreement with the volume distribution calculated from the lognormal fit to the size distribution measured from the aircraft. The largest mode of this 5-mode lognormal distribution was fitted by eye using the Sun photometer data while the other four modes were fitted using the in situ PCASP data. The fitting of this distribution is discussed in more detail by Haywood et al. [2003]. It is worth noting that retrievals from ground-based instruments give a column integrated measure of size distribution and optical depth, which is not ideal for comparing with in situ measurements of size distribution. However, it is likely to in fact be more appropriate for our purposes in this study; calculating the radiative impact at the top of the atmosphere or the surface due to dust.

[24] Few estimates of refractive indices for dust at these wavelengths are available. Three were used in this study. The real and imaginary parts of these refractive indices across the window region are shown in the upper and lower panels respectively of Figure 5. The "WMO" indices are taken from $W C P$ [1986] and are used in several of the climate models that include dust. The "Fouquart" and
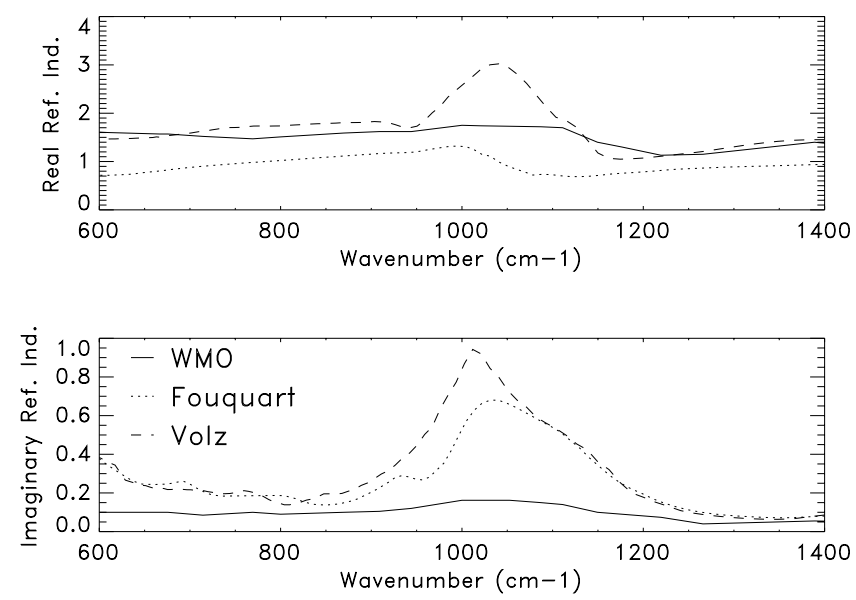

Figure 5. (top) Real and (bottom) imaginary parts of the refractive indices in the terrestrial for various types of dust. Solid line "WMO," "dust-like aerosol" from WCP [1986]; dotted line "Fouquart" Saharan dust collected over Niger [Fouquart et al., 1987]; dashed line "Volz," Saharan dust collected at Barbados [Volz, 1973]. 

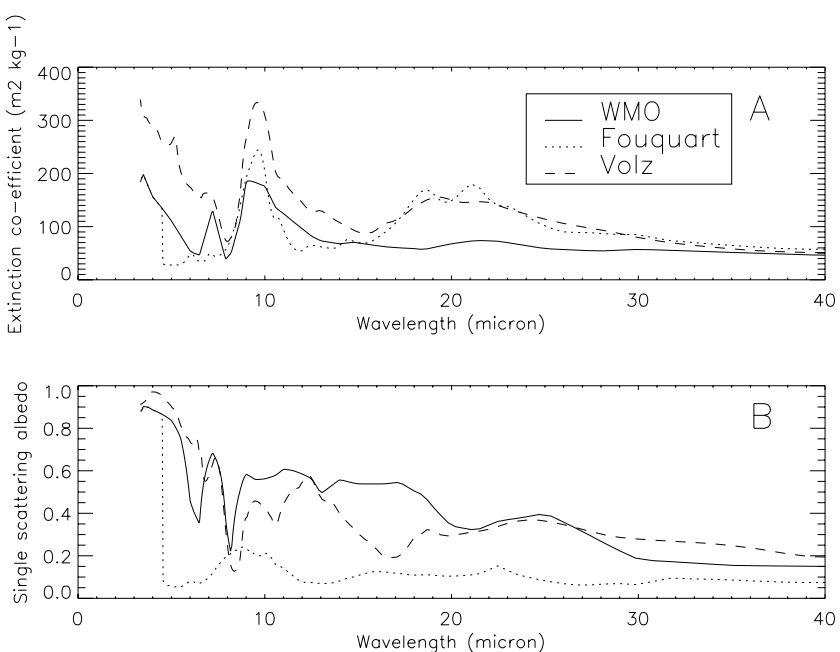

Figure 6. Sensitivity of single scattering properties in the terrestrial region of the spectrum to refractive indices used. (a) Extinction coefficient $\left(\mathrm{m}^{2} \mathrm{~kg}^{-1}\right)$; (b) single scattering albedo. Solid line, "WMO"; dotted line, "Fouquart"; dashed line, "Volz" (as described in caption to Figure 4).

"Volz" indices are taken from measurements of sand samples at Niger [Fouquart et al., 1987] and Barbados [Volz, 1973] respectively. It is immediately obvious that there are some large differences in both the real and imaginary parts of these indices. In particular, the peak in absorption at around $1050 \mathrm{~cm}^{-1}$ present in the Volz and Fouquart indices is due to quartz absorption and is almost entirely missing in the WMO indices. In general the WMO indices show much less spectral variation than the other descriptions.

[25] These refractive indices have been used together with the size distribution retrieved from the Sal Sun photometer and shown in Figure $4 \mathrm{~b}$ and Mie scattering theory to calculate the extinction coefficient, single scattering albedo and asymmetry parameter. (In fact we calculate and subsequently use 21 moments of the full scattering phase function.) Figure 6 shows the spectral variation of extinction coefficient (upper panel) and single scattering albedo (lower panel) in the terrestrial using the Nakajima 1652 size distribution and the three different refractive indices. Clearly the single scattering properties are very sensitive to the refractive index used. The sensitivity to size distribution was also tested by comparing the single scattering properties calculated using the average of Nakajima and Dubovik et al. retrieved size distribution, and found to be very small compared to the effect of the refractive index.

\subsection{Simulated Brightness Temperatures: Nadir Views}

[26] Figure 7a shows the effect on brightness temperature of using the same mass loading of dust and atmospheric profiles of temperature, ozone and water vapor with different refractive indices to represent the dust. The dust mass loading is equivalent to an optical depth at 0.55 microns of 0.67 , within the range of optical depths retrieved during the time of the flight from the Sun photometers. The optical depth in the terrestrial spectrum is obviously a function of the refractive indices as well as the total mass. A simple ratio between mass extinction coefficient at 0.55 and
$10.0 \mu \mathrm{m}$ results in the "terrestrial optical depth" being 0.23 for WMO, 0.25 for Fouquart and 0.40 for Volz, using identical mass mixing ratio profiles. The heavy solid curve in Figure $7 \mathrm{a}$ is the nadir view ARIES measurements from run 6 , degraded to the $10 \mathrm{~cm}^{-1}$ resolution of the model output. The dot-dashed curve is a model simulation with clear sky (no dust) and the same surface temperature as the ARIES data. (It was previously checked that the radiance code gave good agreement with the ARIES instrument in a clear sky case, therefore any difference between ARIES in the presence of dust and our radiance model is due to misrepresentation of the dust [Silverstone, 2002]).
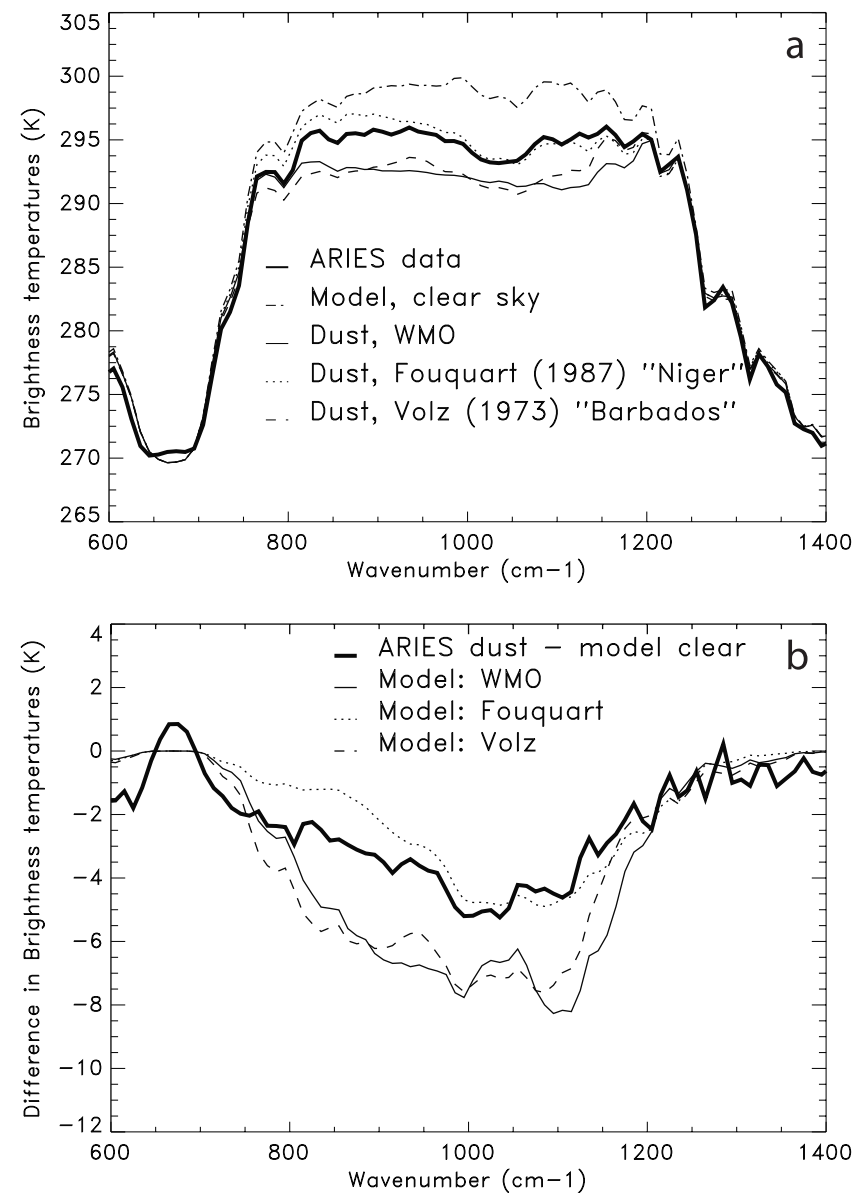

Figure 7. (a) Brightness temperatures modeled using the radiance version of the Edwards and Slingo [1996] code and different refractive indices. A constant mass loading of dust is used corresponding to a visible optical depth of 0.67 . Heavy solid line is ARIES observations from run 6 (Figure 2a) degraded to the same $10 \mathrm{~cm}^{-1}$ resolution as the model.; solid line is model simulation using "WMO" refractive indices; dotted line is simulation with "Fouquart" indices, dashed line is simulation with "Volz" indices; dotdashed line is simulation of clear sky brightness temperatures. (b) Spectral signature of dust in modeled brightness temperature (dusty to clear conditions). Heavy solid line is the ARIES data in dusty sky minus the clear sky simulation since the ARIES clear sky data was at a different sea surface temperature. Other lines are the differences between dusty and clear conditions for the various refractive indices. 

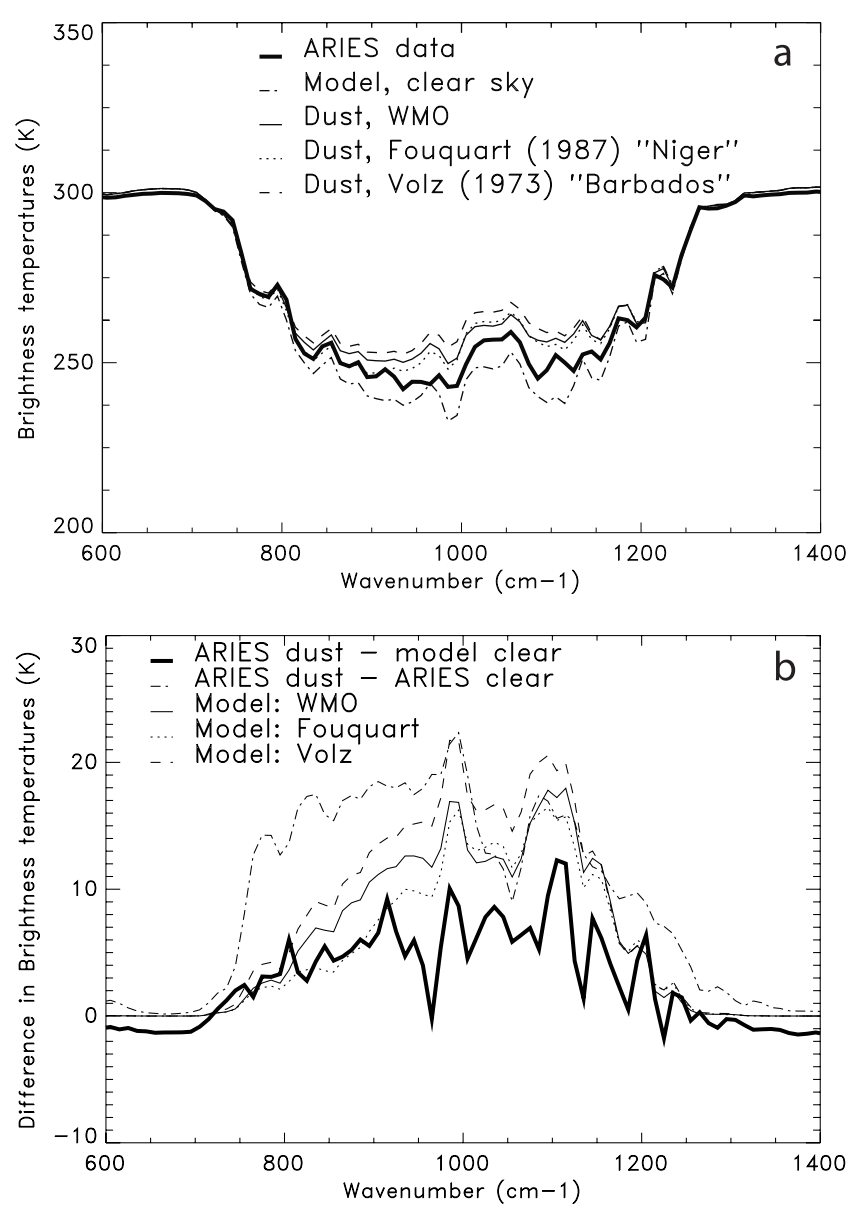

Figure 8. (a) Zenith view brightness temperature simulations and (b) zenith view spectral signatures. Lines as for Figure 6 but with the addition in Figure $8 \mathrm{~b}$ of the dot-dashed line, which is the spectral signal calculated from ARIES data in dusty and clear sky (i.e., a spectrally degraded version of Figure $2 b$ ).

[27] The three model simulations with different refractive indices give very different spectral variation of brightness temperature, even for the same mass loading. The WMO simulation shows very little spectral variation, not surprisingly given the featureless nature of the refractive index and single scattering properties shown in Figures 5 and 6 respectively. The Fouquart simulation (dotted line in Figure 7a) appears to give the best agreement with the ARIES data for this mass loading.

[28] Figure $7 \mathrm{~b}$ shows the spectral signal in brightness temperature from the model simulations, in comparison with that calculated from the ARIES data and a model simulation of clear sky (to eliminate any problems with differing sea surface temperatures). Within the window region the Fouquart simulation gives clearly the spectral signal in best agreement with the one derived from the ARIES data. The differing shape of the signal at $650 \mathrm{~cm}^{-1}$ reflects a difference in the gaseous absorption between the model and the observations in the strong $\mathrm{CO}_{2}$ band centered at $670 \mathrm{~cm}^{-1}$.

4.4. Simulated Brightness Temperatures: Zenith Views

[29] Figure 8a shows the modeled zenith view effect of dust in comparison with those from the ARIES observa- tions. In this case all the simulations appear to give a reasonable representation of the ARIES data at first glance and it is not obvious that any one of the simulations gives better agreement although the Fouquart simulation is consistently closest to the ARIES measurements. The observed and modeled brightness temperatures are different by about $5-10^{\circ}$ in the window region although the spectral shape is similar. The difference between the models is of a similar magnitude. Differences between the models and the observations become more apparent when we compare the spectral signatures in Figure $8 \mathrm{~b}$. As before the ARIES spectral signature has been calculated here by removing the simulated clear sky brightness temperature. It shows some similarities to the simulated spectral signatures but the shape is rather different at wave numbers between 750 and $900 \mathrm{~cm}^{-1}$. Zenith view simulations are more dependent on getting a good representation of the atmospheric profile above the dust layer than are the nadir view simulations. Also shown in Figure 8b (the dot-dashed line) is the spectral signal calculated from subtracting the clear sky case ARIES measurements from the dusty ARIES measurements. (The zenith views should not be affected by differing sea surface temperatures so long as the atmospheres were similar on the two days.) It is obvious that this spectral signal has a rather different appearance than those simulated, or that calculated from ARIES dusty data and the clear sky simulation. This is an indication that the assumption of the atmospheres on the two days when ARIES data was used being similar may not be very realistic. The nadir view results are not affected by this as strongly.

\subsection{Brightness Temperatures: Uncertainties}

[30] Other influences on the quality of the modeling of the dust radiative effect could include errors in sea surface temperature, aerosol mass loading and vertical variation, size distribution and the atmospheric profiles of other gases. The SST measurements are known to be accurate to around $0.5 \mathrm{~K}$. Figure 9a shows the influence of these uncertainties on the brightness temperature simulations for nadir view using the Fouquart refractive indices to be small, certainly very much smaller than the effect of the differing refractive indices.

[31] Figure 9b shows the effect of different mass loadings. The aerosol profile shape has been constrained and the mass mixing ratio scaled to give 0.55 micron optical depths (WMO refractive indices in the visible) of between 0.3 and 1.3 , i.e., the range observed by the Sun photometer. Different mass loadings can change the degree of general agreement between the ARIES data and the simulation, but not the spectral signature itself, that coming from the refractive indices used. However, it is clear that it is important to know the mass loading to get full consistency between observations and the model.

[32] Figure 9c shows the effect of uncertainties in the temperature profile. Simulations were completed using two temperature profiles created by adding (or subtracting) the standard deviation of temperature at each level to the average profile created from the 4 dropsonde descents during run 6 . As with sea surface temperatures the different atmospheric temperature profiles have only a small effect on the brightness temperature. Uncertainties in the ozone profile and water vapor profile had a negligible 

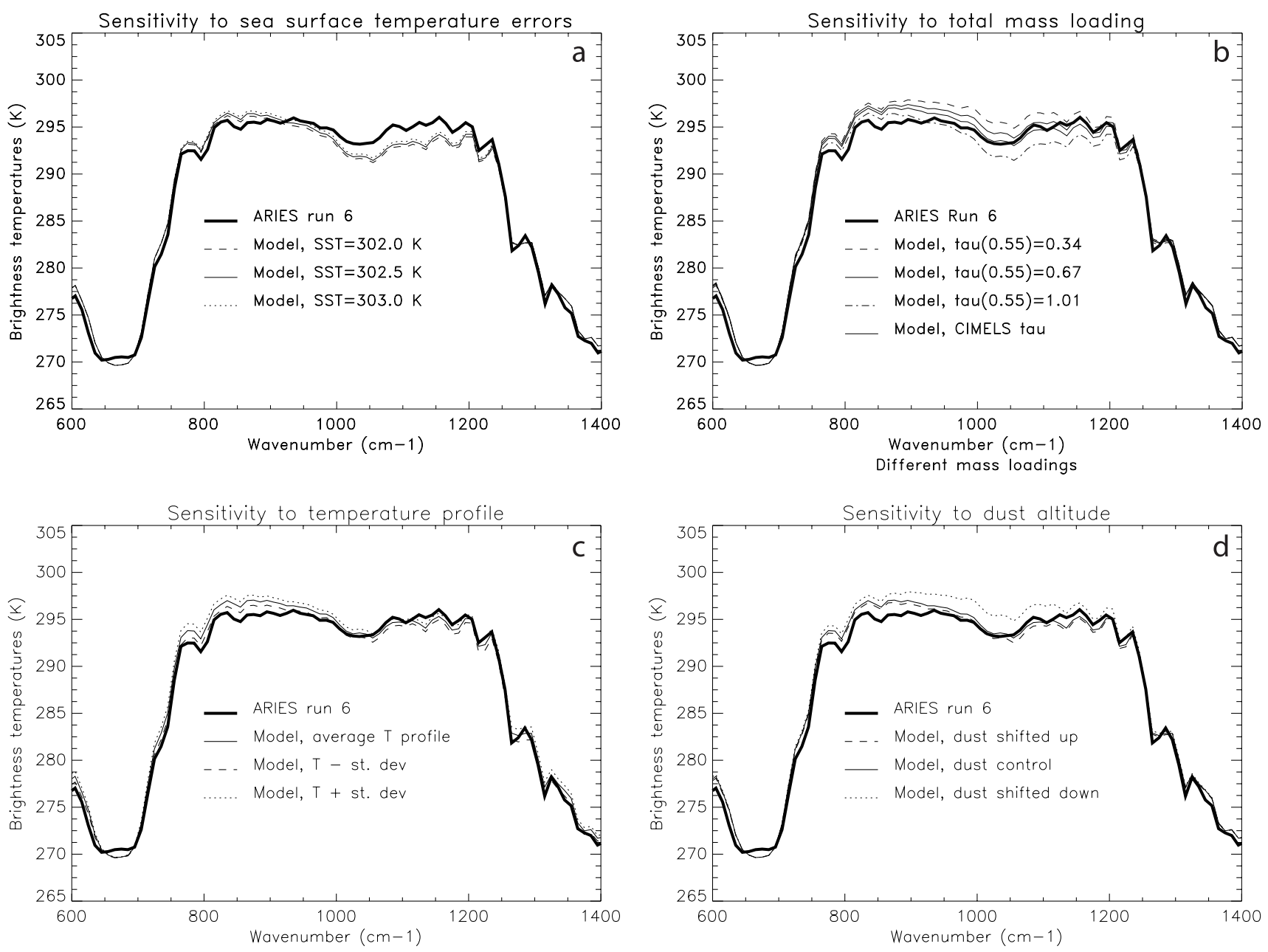

Figure 9. Effect of known uncertainties on brightness temperatures (a) sea surface temperature, (b) dust mass loading, (c) temperature profile, and (d) altitude of dust layer. For full explanations of these sensitivity studies, see the main text. Table 1 summarizes the maximum range of brightness temperature for each type of uncertainty.

effect within the window region for these nadir view simulations.

[33] The altitude of the dust layer itself however has a considerable effect on the simulated brightness temperatures as shown in Figure 9d. The dust layer in the profile shown in Figure 3d lies approximately between 875 and $590 \mathrm{mb}$. The dust mixing ratio profile was shifted up and down by a number of layers keeping the total optical depth constant. When the dust layer was shifted down (now lying between $969 \mathrm{mb}$ and $680 \mathrm{mb}$ ) the brightness temperatures simulated increase by around $3 \mathrm{~K}$, a considerable amount relative to the effect of having dust there at all $(4 \mathrm{~K})$. This is due to moving the dust layer to warmer temperatures such that its addition to a clear sky column produces less reduction in upwelling terrestrial radiation. When the dust layer was moved to lie between 775 and $400 \mathrm{mb}$ there was less change in effect on the brightness temperatures from the standard profile.

[34] Table 1 shows the maximum range of modeled brightness temperatures for each sensitivity study at two wavelengths, one on either side of the strong ozone absorption band. It can clearly be seen that the largest range in brightness temperatures comes from varying the refractive index and the total mass loading within the range of uncertainties associated with this particular measurement period. Thus it is concluded that the uncertainties in the refractive indices, the mass loading and the vertical position of the dust layer are the dominant factors in creating uncertainty in the magnitude of the radiative effect of dust. The size distribution is much less important so long as the large particles are measured. Given a reasonably well constrained size distribution, the shape of the spectral signature is predominantly determined by the refractive indices used and observations of this signature could therefore be used to constrain the refractive indices for dust in the terrestrial spectrum. The magnitude of the dust radiative effect is affected predominantly by the refractive indices, but significantly by uncertainties in the total mass loading and altitude of the dust layer.

\subsection{Irradiance}

[35] The Fouquart refractive indices and Sun photometer size distribution that gave closest agreement with the ARIES observations at least in the nadir views are now 
Table 1. Maximum Range in Brightness Temperature at Two Wave Numbers 900 and $1100 \mathrm{~cm}^{-1}$ From Model Simulations of Brightness Temperature Including Dust ${ }^{\mathrm{a}}$

\begin{tabular}{lcc}
\hline \multicolumn{1}{c}{$\begin{array}{c}\text { Source of } \\
\text { Uncertainty }\end{array}$} & $\begin{array}{c}\text { Range in Brightness } \\
\text { Temperature at } 900 \mathrm{~cm}^{-1} \mathrm{~K}\end{array}$ & $\begin{array}{c}\text { Range in Brightness } \\
\text { Temperature at } 1100 \mathrm{~cm}{ }^{-1} \mathrm{~K}\end{array}$ \\
\hline Refractive index & 5.0 & 6.5 \\
Total dust mass (optical depth) & 2.0 & 2.5 \\
Temperature profile & 1.0 & 0.3 \\
Dust altitude & 1.0 & 2.0 \\
Sea surface temperature & 0.7 & 0.7 \\
Size distribution & $\sim 0.1$ & $\sim 0.1$ \\
Variation between different parts of run 6 & 2.0 & 2.0 \\
\hline
\end{tabular}

${ }^{\mathrm{a}}$ In each case the uncertainties used were those measured or documented during flight a797 (except for refractive index where the uncertainty is introduced by using 3 different measurements as described in the text). The variation between different parts of run 6 is largely due to different optical depths of dust being present during different parts of the run.

used to estimate the "radiative effect" of the dust, i.e., the impact on irradiance at the top of the atmosphere and the surface. Calculations with the Edwards and Slingo [1996] model give a radiative effect of $6.5 \mathrm{Wm}^{-2}$ (i.e., a reduction in outgoing terrestrial radiation of $6.1 \mathrm{Wm}^{-2}$ ) at the top of the atmosphere and $11.5 \mathrm{Wm}^{-2}$ (i.e., an increase of $11.5 \mathrm{Wm}^{-2}$ ) at the surface for this dust outbreak.

[36] Although this effect is an order of magnitude smaller than the radiative effect in the shortwave, it is not insignif-
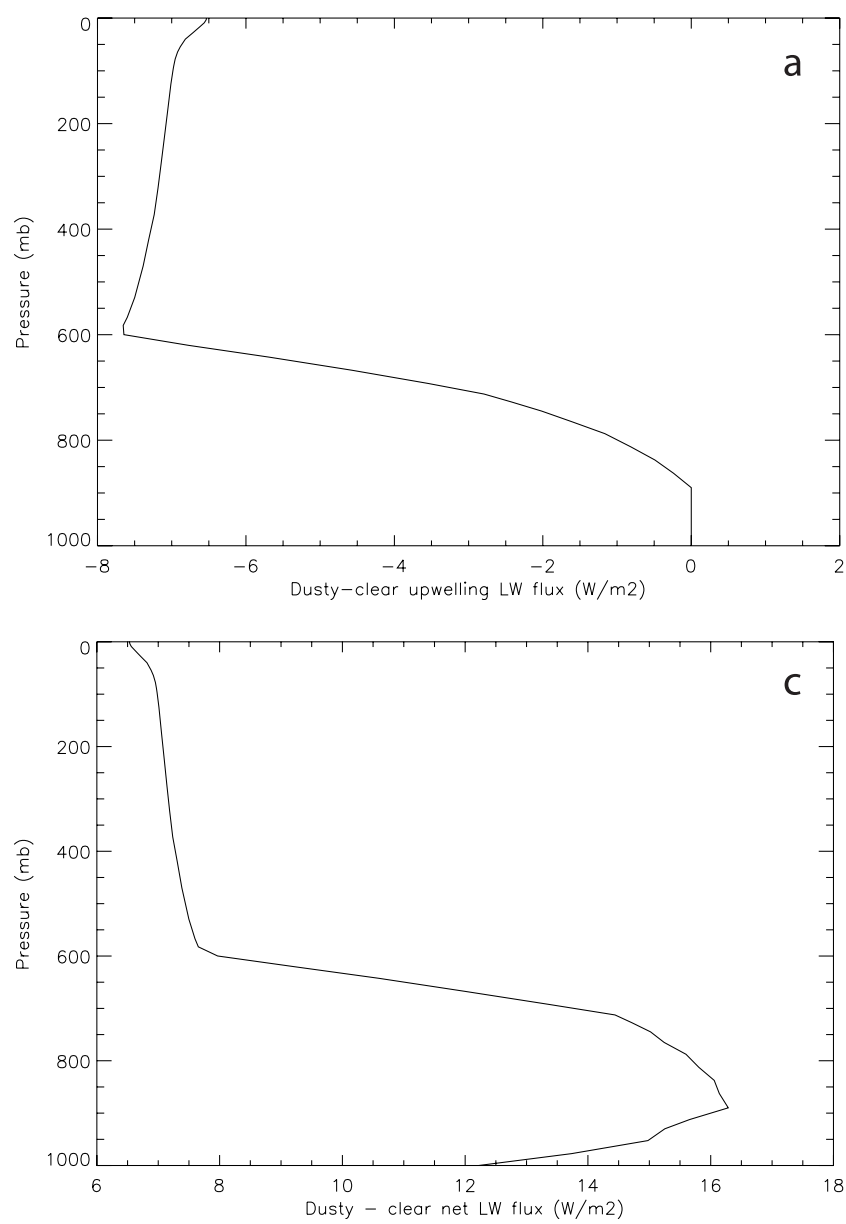

icant. The top of the atmosphere estimate is about $50 \%$ of that calculated for a heavy dust loading by Sokolik et al. [1998], while the surface effect is considerably smaller than that found in the same study. Figure 10 shows the difference in irradiance as a function of height between clear and dusty simulations. The largest reduction of upwelling radiation (Figure 10a) occurs near the top of the cloud while the peak increase in downwelling radiation (Figure 10b) occurs near the base of the cloud. The peak effect in net radiation
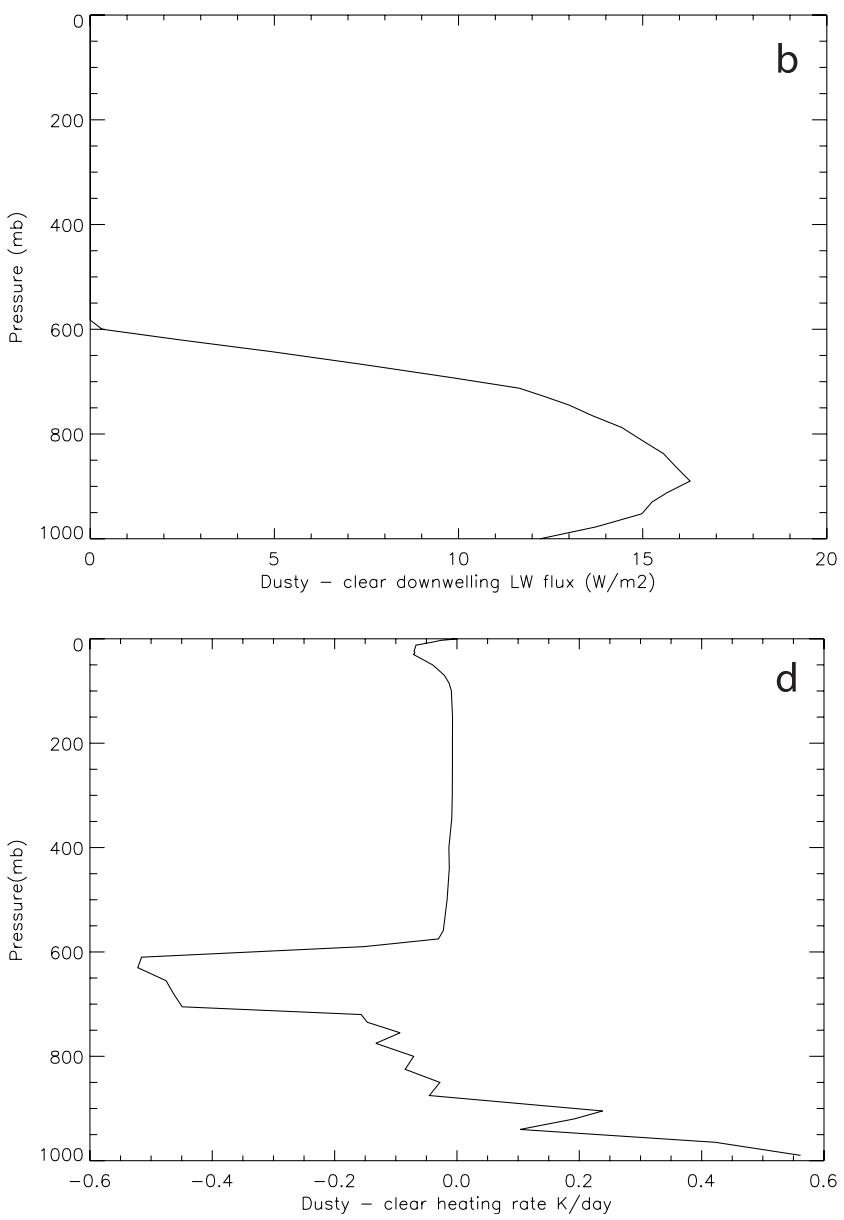

Figure 10. Difference between terrestrial irradiance $\left(\mathrm{Wm}^{-2}\right)$ in dusty and clear sky simulations using the Edwards and Slingo [1996] model. (a) Upwelling flux, (b) downwelling flux, (c) net downward flux, and (d) heating rate. 

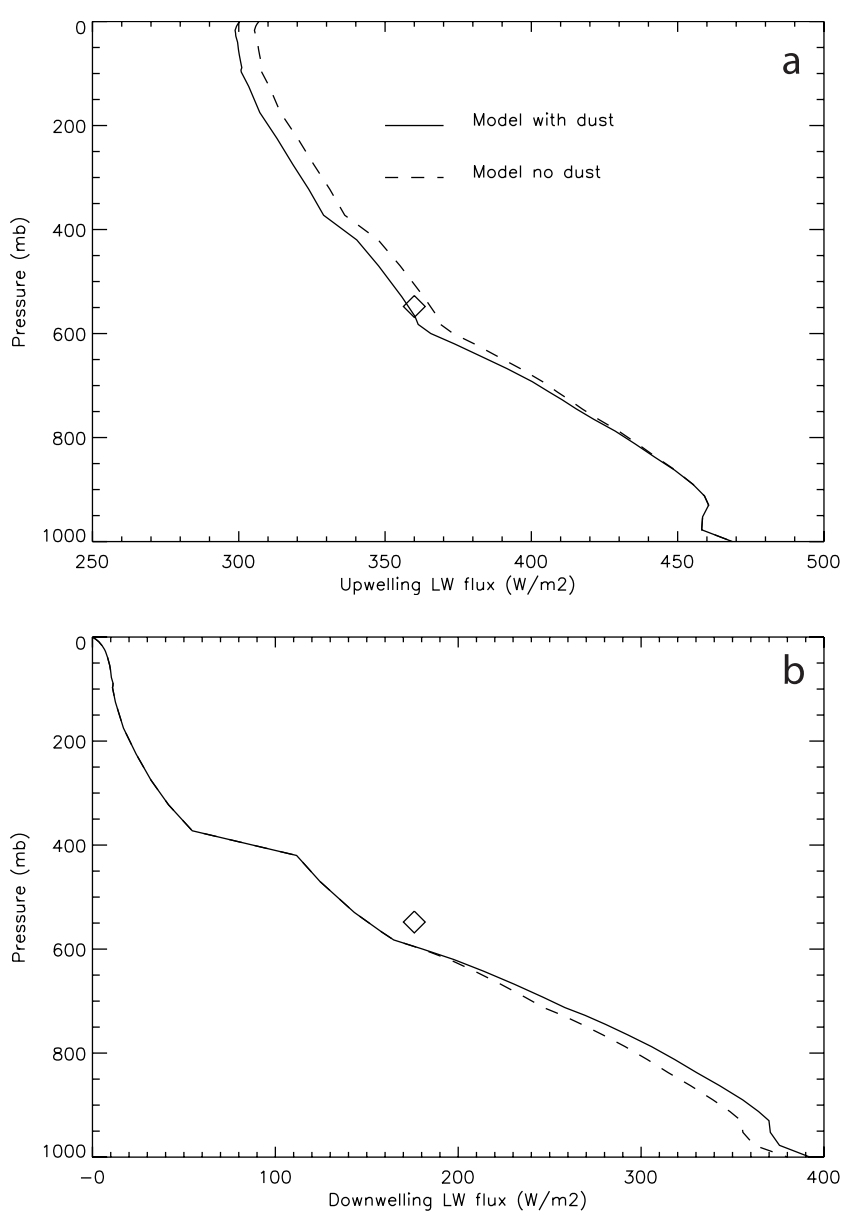

Figure 11. Comparison between modeled irradiances and measurements from broadband radiometers during run 6 . (a) Upwelling terrestrial radiation and (b) downwelling terrestrial radiation. Solid lines are model simulation with dust in the profile; dashed lines are model simulation with no dust. Diamonds represent the BBR observations at the flight level of run 6 (average over whole run).

(Figure 10c) is therefore at around $900 \mathrm{mb}$. This relationship to the dust profile is in accordance with previous studies.

[37] The terrestrial (negative) heating rates are modified by the presence of the dust affecting terrestrial radiation by up to $10 \%$ of their clear sky value. There is a strong relative warming below the cloud and at the surface $(0.5 \mathrm{~K} /$ day $)$ with relative cooling throughout most of the dust layer (Figure 10d). A small secondary peak in relative cooling occurs in the stratosphere since there is less upwelling terrestrial radiation to be absorbed by the ozone layer. The larger additional heating and cooling rates further down could have an effect on local dynamics; in this case the dust is fairly low in the atmosphere and the atmospheric lapse rate would be increased.

[38] Figure 11 shows how the simulated irradiances compare to the broad-band radiometer (BBR) measurements. The BBR measurements are marked as diamonds while the model simulations in dusty skies are the solid lines. The simulation of the upwelling flux from the dust layer (Figure 11a) is in good agreement with the observations from the BBRs. The simulation of downwelling flux (Figure 11b) agrees some- what less well with the BBR measurement; this is not surprising given that the downwelling radiation is quite sensitive to the temperature and humidity profiles used.

[39] Sokolik et al. [1998] calculated the radiative effect of dust using different refractive indices with lognormal distributions and showed that the terrestrial forcing at the surface using the Fouquart refractive indices was 35\% larger and the forcing at the top of the atmosphere $12 \%$ smaller than those calculated using the WMO refractive indices. Similar results are found here using the measured size distribution and dust profile; the surface forcing is $38 \%$ larger while the top of the atmosphere forcing is $1 \%$ smaller than using the WMO indices.

\section{Effect on AVHRR Retrievals of SST}

[40] The AVHRR SST retrieval uses a dual window technique whereby the radiances in Channel $4\left(880-960 \mathrm{~cm}^{-1}\right)$ and Channel $5\left(800-870 \mathrm{~cm}^{-1}\right)$ are used to derive the SST. Examination of Figure 1 reveals that these channels are in the spectral region influenced by the presence of mineral dust. To investigate whether AVHRR retrievals are contaminated by mineral dust, the following method was adopted. Total Ozone Mapping Satellite (TOMS) aerosol index data were used to determine when the operating area was free from dust and when the aerosol loading was a maximum. The dust-free case was from data from 23-24 September, and the maximum dust loading was from 26-27 September and is available from the NOAA Satellite Active Archive (http://www.saa.noaa.gov). The data is compiled over 2 days to improve sampling and cloud screening. SSTs from the dusty period were then subtracted from those from the dust-free period to examine if there was a significant effect on the AVHRR derived SSTs. The results are shown in Figure 12. It can clearly be seen that an SST anomaly of

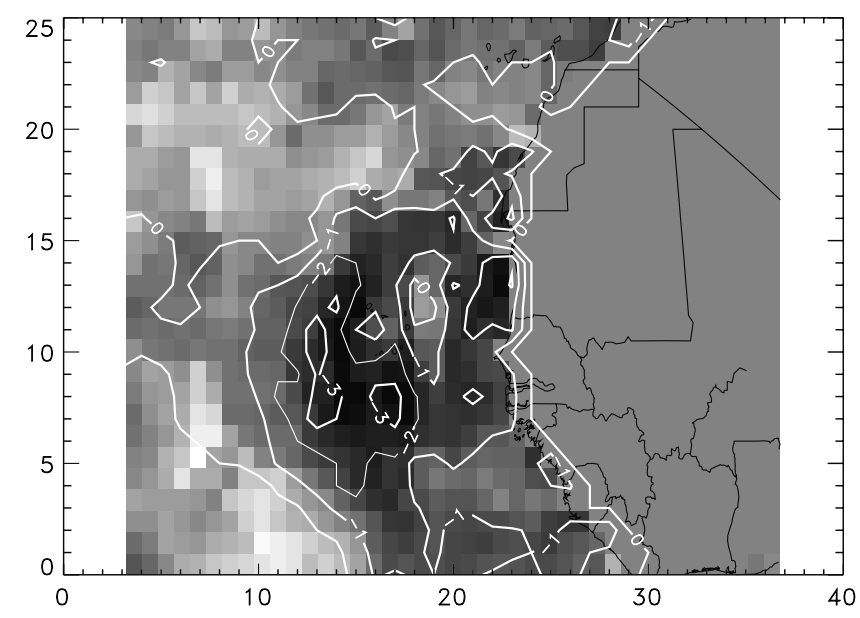

Figure 12. Difference in sea surface temperature in the eastern tropical Atlantic retrieved from AVHRR during a dust storm and that retrieved on a day with no dust present. Contour interval is $1 \mathrm{~K}$. The dust-free case was from data from 23-24 September, and the maximum dust loading was from 26-27 September and is available from the NOAA Satellite Active Archive (http://www.saa.noaa.gov). The data is compiled over 2 days to improve sampling and cloud screening. 
greater than $-3 \mathrm{~K}$ exists over the area affected by the dust storm.

[41] Although the downwelling irradiance at the surface at terrestrial wavelengths increases as a result of the dust $\left(\Delta \mathrm{F}_{1 \mathrm{w}}\right)$, there is a substantial reduction in irradiance at visible wavelengths (maximum $\Delta \mathrm{F}_{\mathrm{sw}}=-130 \mathrm{Wm}^{-2}$ in the work of Haywood et al. [2003]). The expected ocean heating rate due to the presence of dust can be estimated using these values. Assuming the dust produces an impact on terrestrial radiation throughout the day but on the solar radiation for half the day, the implied cooling rate of the ocean (units $\mathrm{K}$ per day) due to dust can be written as:

$$
\dot{T}=\frac{86400^{*} \Delta F_{l w}-43200^{*} \Delta F_{s w}}{\rho_{w}^{*} d^{*} c_{p}},
$$

where $d$ is the depth of the heated layer, $\rho_{\mathrm{w}}$ the density of water and $c_{p}$ the specific heat capacity of water. The maximum cooling rate calculated by this method is approximately $-0.1 \mathrm{~K} /$ day (assuming a likely minimum mixed layer depth due to wind forcing of $10 \mathrm{~m}$ ). Over a period of a few days then it seems unlikely that the dust alone could cause a real drop of over $3 \mathrm{~K}$ in sea surface temperature and the anomaly in Figure 12 is more likely due to the retrieval not taking account of the dust in the profile. In other cases, there have been problems with dust being misdetected as cloud in retrieval algorithms [Haywood et al., 2001]. It is therefore important to know enough about the dust properties at the wavelengths of the satellite channels used for such retrievals to be able to quantify the likely impact of these dust events on sea surface temperature retrievals. This cannot be done without in situ measurements.

\section{Discussion and Conclusions}

[42] This study has reported novel high spectral resolution in situ measurements of the radiative effect of Saharan dust on terrestrial radiation. The observed spectral signature of dust in terrestrial radiation has also been modeled; the agreement between model and observations being very sensitive to the refractive indices used.

[43] Saharan dust gives a distinct spectral signal in the atmospheric window region which can be clearly seen in the high spectral resolution data from ARIES measurements both above and below the dust layer. The small signal observable above the dust layer could perhaps be used by satellite instruments to allow the identification of areas affected by dust. This would be of interest for assessing the effect of the dust on radiation and on the retrievals of other quantities. There is a larger signal observable in the downwelling radiation below the dust and this may be of use in interpreting ground-based measurements.

[44] The refractive index of the dust in the terrestrial part of the spectrum is the dominant uncertainty which restricts the accuracy of our simulations of the dust radiative effect. The spectral signal observed in the nadir view ARIES data can be most successfully simulated using visible optical depths of dust consistent with in situ observations if we use the refractive index measurements of Fouquart et al. [1987] in the terrestrial spectrum. This suggests that for representing Saharan dust in climate models, aerosol optical properties should be derived using these refractive indices (certainly in preference to the widely used WMO "dustlike" indices of WCP [1986]). The simulations of the zenith view ARIES data are somewhat less conclusive. Since the mineral composition of dust is strongly dependent on the source region, more measurements such as have been presented in this study must be made over other source regions before we can identify if there is a suitable "global" dust that can be used in climate models. The changes in aerosol properties at distances further from the source should also be measured. It is also fundamentally important that the size distributions measure large nonspherical particles, unlike the current instrumentation on the C-130.

[45] The radiative effect of this dust storm was a decrease of $6.5 \mathrm{Wm}^{-2}$ at the top of the atmosphere and an increase of $11.5 \mathrm{Wm}^{-2}$ at the surface, giving additional heating rates of up to $0.5 \mathrm{~K}$ /day at the surface and $-0.5 \mathrm{~K}$ /day within the dust cloud. These irradiance changes are somewhat less than those in previous studies but are heavily dependent on dust loading and refractive indices used. The terrestrial changes are of the order of $10 \%$ of those due to solar radiation (and of the opposing sign). The effect of using different refractive indices is up consistent with other studies; the recommended refractive indices giving a 38\% larger surface forcing but similar top of atmosphere forcing to calculations with the WMO refractive indices.

[46] Changes in brightness temperature in the window region due to the presence of the dust are of a similar magnitude to the regional temperature differences observed in AVHRR sea surface temperature retrievals when comparing clear and dusty days. Information about the interaction of dust and radiation of the kind that has been revealed in this study could be used to revise satellite retrieval algorithms and to update the dust radiative parameters currently used in climate modeling. In addition, knowledge of the spectral signature of dust could be exploited to remotely monitor dust outbreaks. The near-future mission of MSG-2 carrying GERB and SEVIRI will allow an assessment of the frequency and magnitude of similar dust outbreaks in this region and of the aerosol characteristics. It will then also be possible to quantify the role of these dust outbreaks in affecting the energy balance of the present-day climate system.

[47] The unique combination of high-quality in situ measurements and sophisticated radiative transfer models used in this study and the other papers in this special section has been able to highlight the fundamental parameters causing large uncertainties in estimates of the radiative impact of Saharan dust. However, it is still only one intensive campaign over one dust source area. Further coordinated measurement campaigns using satellite, in situ and ground-based radiation and aerosol measurements will be necessary both in the Saharan region and over other dust source areas before a coherent picture of the magnitude and extent of the radiative effect of dust in global terms will become apparent. Only then will we be able to go some way to reducing (or even merely quantifying) the uncertainties in current estimates of radiative forcing due to changes in atmospheric dust burden.

[48] Acknowledgments. MDS was supported by a NERC studentship. EJH thanks all the staff at the Met Office research flight in Farnborough for letting her have disk and desk space for the past year and a half, and for access to the SHADE data. Oleg Dubovik is thanked for making available the Dubovik et al. [2002] retrieval discussed in section 4.2. Didier 
Tanré is thanked for making the other aerosol size distributions used in this work available via the AERONET website. Keith Shine is thanked for many helpful discussions during the course of this work.

\section{References}

Dubovik, O., and M. D. King, A flexible inversion algorithm for retrieval of optical properties from Sun and sky radiance measurements, J. Geophys. Res., 105, 20,673-20,696, 2000.

Dubovik, O., B. N. Holben, T. Lapyonok, A. Sinyuk, M. I. Mishchenko, P. Yang, and I. Slutsker, Non-spherical aerosol retrieval method employing light scattering by spheroids, Geophys. Res. Lett., 29(10), 1415, doi:10.1029/2001GL014506, 2002.

Edwards, J. M., and A. Slingo, Studies with a flexible new radiation code, I: Choosing a configuration for a large-scale model, Q. J. R. Meteorol. Soc., 122, 689-720, 1996.

Foot, J., A new pyrogeometer, J. Atmos. Oceanic. Technol., 3, 363-370, 1986.

Fouquart, Y., B. Bonnel, G. Brogniez, J. C. Buriez, L. Smith, and J. J. Morcrette, Observations of Saharan aerosols: Results of ECLATS field experiment, part II, Broadband radiative characteristics of aerosols and vertical flux divergence, J. Clim. Appl. Meteorol., 26, 38-52, 1987.

Haywood, J. M., P. N. Francis, M. D. Glew, and J. P. Taylor, Optical properties and direct radiative effect of Saharan dust: A case study of two Saharan dust outbreaks using aircraft data, J. Geophys. Res., 106, 18,417-18,430, 2001.

Haywood, J. M., et al., Radiative properties and direct radiative effect of Saharan dust measured by the C-130 aircraft during Saharan Dust Experiment (SHADE): 1. Solar spectrum, J. Geophys. Res., 108(D18), doi:10.1029/2002JD002687, in press, 2003.

Masuda, K., T. Takashima, and Y. Takayama, Emissivity of pure and sea waters for the model sea-surface in the infra-red window regions, Remote Sens. Environ., 24, 313-329, 1998.

McClatchley, R. A., R. W. Fenn, J. E. A. Volz, and J. S. Garing, Optical properties of the atmosphere, Environ. Res. Pap. 411, Air Force Cambridge Res. Lab., LG Hanscom Field, Bedford, Mass., 1972.

Mishchenko, M. I., L. D. Travis, R. A. Kahn, and R. A. West, Modeling phase functions for dust-like tropospheric aerosols using a shape mixture of randomly oriented polydisperse spheroids, J. Geophys. Res., 102, $16,831-16,847,1997$.

Myhre, G., and F. Stordal, Global sensitivity experiments of the radiative forcing due to mineral aerosols, J. Geophys. Res., 106, 18,193-18,204, 2001 .
Nakajima, T., G. Tonna, R. Rao, P. Bio, Y. J. Kaufman, and B. N. Holben, Use of sky brightness measurements from ground for remote sensing of particulate polydispersions, Appl. Opt., 35, 2672-2886, 1996.

Newman, S. M., and J. P. Taylor, Impact of updates to the HITRAN spectroscopic database on the modeling of clear-sky infrared radiances, Geophys. Res. Lett., 29(20), 1957, doi:10.1029/2002GL015832, 2002.

Quijano, A. L., I. N. Sokolik, and O. B. Toon, Radiative heating rates and direct radiative forcing by mineral dust in cloudy atmospheric conditions, J. Geophys. Res., 105, 12,207-12,219, 2000.

Silverstone, M., Radiative effect of mineral dust, M.S. thesis, Univ. of Reading, Reading, UK, 2002.

Sokolik, I. N., and O. B. Toon, Direct radiative forcing by anthropogenic mineral aerosols, Nature, 381, 681-683, 1996.

Sokolik, I. N., and O. B. Toon, Incorporation of mineralogical composition into models of the radiative properties of airborne mineral aerosols from IV to IR wavelengths, J. Geophys. Res., 104, 9423-9444, 1999.

Sokolik, I. N., O. B. Toon, and R. W. Bergstrom, Modeling the radiative characteristics of airborne mineral aerosols at infrared wavelengths, J. Geophys. Res., 103, 8813-8826, 1998.

Sokolik, I. N., D. M. Winker, G. Bergamenti, D. A. Gillette, G. Carmichael, Y. J. Kaufman, L. Gomes, L. Schuetz, and J. Penner, Introduction to special section: Outstanding problems in quantifying the radiative impacts of mineral dust, J. Geophys. Res., 106, 18,015-18,028, 2001.

Volz, F. E., Infrared refractive index of atmospheric aerosol substances, Appl. Opt., 11(4), 755-759, 1972.

Volz, F. E., Infrared optical constants of ammonium sulphate, Sahara dust, volcanic pumice and flyash, Appl. Opt., 12(3), 564-567, 1973.

World Climate Program (WCP), A preliminary cloudless standard atmosphere for radiation computation, World Meteorol. Org., Geneva, 1986.

J. M. Haywood and S. M. Newman, Met Office (MRF), Building Y46, Cody Techology Park, Ively Road, Farnborough, Hampshire GU14 OLX, UK.(j.m.haywood@metoffice.com; stu.newman@metoffice.com)

E. J. Highwood, Department of Meteorology, University of Reading, PO Box 243, Reading RG6 6BB, UK. (e.j.highwood@reading.ac.uk)

M. D. Silverstone, Met Office, London Road, Bracknell, Berkshire RG12 2SZ, UK. (Michael.Silverstone@metoffice.com)

J. P. Taylor, Met Office, Building Y70, Technology Park, Ively Road, Farnborough, Hampshire GU14 OLX, UK. (jonathan.p.taylor@metoffice. com) 